\title{
Experimental Investigation on the Effects of Various Quenchants on Hardened High Carbon Steels during Lathe Machining
}

\author{
Ogedengbe Temitayo Samson, Abdulkareem Sulaiman and Ogunware Olanrewaju Peter
}

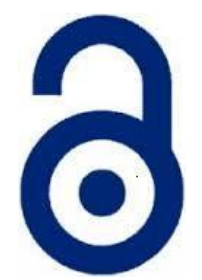

\author{
Received:25 February 2021 \\ Accepted:23 April 2021 \\ Published:01 October 2021 \\ Publisher: Deer Hill Publications \\ (C) 2021 The Author(s) \\ Creative Commons: CC BY 4.0
}

\begin{abstract}
The choice of quenchants during heat treatment of carbon steels can influence the properties of the steel sample. A knowledge of the effect of various quenchants on steel can therefore not be over emphasized. This paper presents results from the experimental investigation on the effects of using brine, water and palm-oil as quenchants during hardening of high carbon steels. Three samples of AISI 1090 high carbon steel (0.95\%wt, Carbon) were furnaceheated at a temperature of $900^{\circ} \mathrm{C}$ in a crucible furnace and quenched using brine, water and oil to harden the steel samples. The hardened steel was machined using a pre-developed design of experiment (DOE). Process parameters during machining were Speed (50-150 rpm), Feed rate (0.3-0.9 mm/min), Depth of Cut (0.1-0.3mm) and Quenchant (water, brine and palm-oil). The responses analysed were surface roughness and tool wear rate. Results show that palm-oil with a lowest surface roughness and hardness $(0.09 \mu \mathrm{m}$ and $150 \mathrm{HB}$, respectively) and highest material removal rate $\left(0.5124 \mathrm{~mm}^{3} / \mathrm{sec}\right)$ was a preferred quenchant as it reduced surface roughness and increased material removal rate (MRR). Hence, Palm oil has proven to be a preferred quenchant during heat treatment of AISI 1090 steel for improved machinability and surface finish.
\end{abstract}

Keywords: Quenchants, Hardening, Material Removal Rate, Surface roughness, High Carbon Steel.

\section{INTRODUCTION}

High carbon steels have found applications in different industries, such as automobile in the manufacture of vehicle spare parts [1]. This is because they are ready available at affordable price and they possess endearing quality which has attracted the interest of machinists and engineers [2]. However, the difficulty encounter in machining steels could result in an increase in costs and reduction in material performance. These had resulted in the exploration of varying methods of increasing the machinability of high carbon steels for engineering applications [3], [4]. Some of such methods include the comparative study of material composition, heat treatment and investigation of thermodynamic properties of cutting fluid types on machinability [2], [4], [5].As reported by [6] and [7], constituent elements and properties of metals could be refined by heat treating, thereby improving machinability of such metals. This submission agrees with [8] who reported that heat treatment can be used to improve hardness, strength, ductility and toughness of materials. Ogedengbe et al. had earlier investigated the influence of heat treatment on some mechanical properties of steels and they suggested the process especially for hot forming of steels [9]. However, the quenching media could affect hardenability of steels [9], [10].In this work, an investigation was carried out on the effects of various quenchants on hardened high carbon steel during machining.

\section{MATERIALS AND METHODS}

2.1 Workpiece Material, Machines and Tools

The workpiece material employed for this research was an AISI 1090 high carbon steel bar (0.95\% wt., Carbon) of length $120 \mathrm{~mm}$ and diameter $35 \mathrm{~mm}$ sourced from the steel market in Akure, Ondo State, Nigeria (Figure 1). The machine used for the turning was an AJAX Model Computer Numerical Control Lathe Machine (Figure 2). The cutting tool utilized for the turning operation was Physical Vapour Deposition (PVD) coated tungsten carbide inserts. The high carbon steel samples were divided into 3 equal parts of $40 \mathrm{~mm}$ length each. The hardening of the steel samples

Ogedengbe T. S. ${ }^{1}$ 凶, Abdulkareem S. ${ }^{2}$, Ogunware O. P. ${ }^{1}$

'Department of Mechanical Engineering

Elizade University, Ondo State, Nigeria

2Department of Mechanical Engineering

University of Ilorin, Kwara State, Nigeria

E-mail: temitayo.ogedengbe@elizadeuniversity.edu.ng

References: Ogedengbe et al. (2021). Experimental Investigation on the Effects of Various Quenchants on Hardened High Carbon Steels during Lathe Machining. International Journal of Engineering Materials and Manufacture, 6(4), 332-339. 
was done using a Brother Electric Muffle Furnace with model number XD-1200N with a maximum temperature capacity of $1100^{\circ} \mathrm{C}$ (Figure 3).

\subsection{Sample Preparation}

The samples were prepared by dividing the parent workpiece material $(120 \mathrm{~mm}$ by $45 \mathrm{~mm}$ ) into 3 equal pieces (40 $\mathrm{mm}$ by $45 \mathrm{~mm}$ ). Each sample was thereafter chamfered to remove sharp edges. The pre-experimental compositional analysis of the steel sample used for this study is presented in Table 1.

\subsection{Heat Treatment/Quenching}

During heat treatment, samples were furnace heated to a temperature of $900^{\circ} \mathrm{C}$ and soaked for a period of 60 minutes. Each of the three soaked samples were thereafter quenched in brine, pure water and Palm oil respectively.

\subsection{Design of Experiment}

The Central Composite Design (CCD) of Response Surface Methodology (RSM) from Minitab software version 18.0 was employed for the design of this experiment. Three factors (cutting speed, depth of cut and feed rate) were used as shown in Table 2 together with their levels. The software was further used to generate an orthogonal array to guide the machining process (Table 3 ).

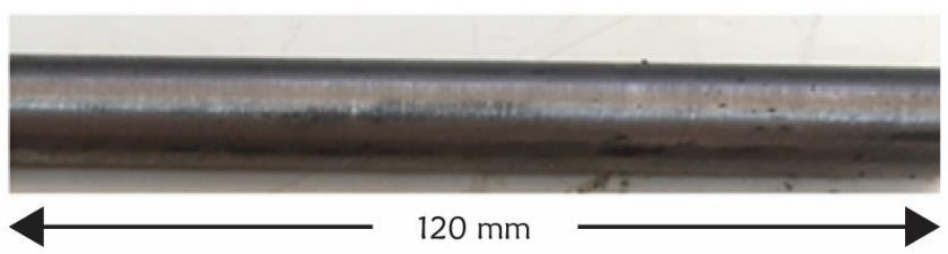

Figure 1: AISI 1090 High Carbon Steel used for study

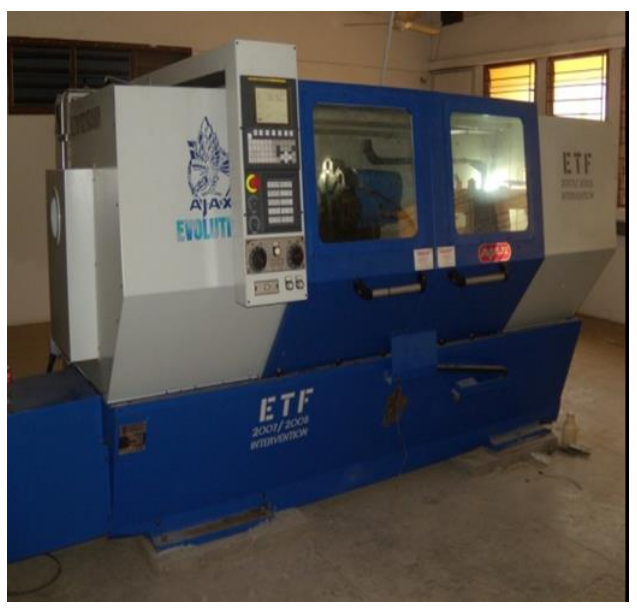

Figure 2: CNC Machine used for study

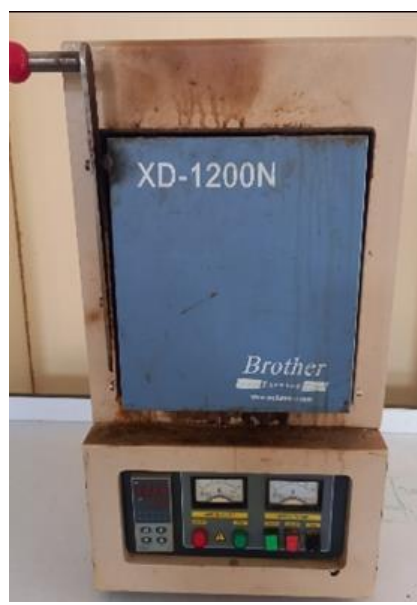

Figure 3: Electric Furnace used for study

Table 1: Compositional Analysis of AISI 1090

\begin{tabular}{cccccccccc}
\hline Element & $\mathrm{Fe}$ & $\mathrm{C}$ & $\mathrm{Mn}$ & $\mathrm{S}$ & $\mathrm{P}$ & $\mathrm{Cu}$ & $\mathrm{Ni}$ & $\mathrm{Sb}$ & $\mathrm{Si}$ \\
\hline$\%$ & 98.2 & 0.95 & 0.65 & 0.02 & 0.01 & 0.02 & 0.016 & 0.084 & 0.05 \\
\hline
\end{tabular}

Table 2: Machining factors and levels for quenched steels

\begin{tabular}{cccc}
\hline Level & Cutting Speed $(\mathrm{m} / \mathrm{min})$ & Feed Rate $(\mathrm{mm} / \mathrm{rev})$ & Depth of Cut $(\mathrm{mm})$ \\
\hline 1 & 50 & 0.3 & 0.1 \\
2 & 100 & 0.6 & 0.2 \\
3 & 150 & 0.9 & 0.3 \\
\hline
\end{tabular}


Table 3: Orthogonal Array for Experimentation

\begin{tabular}{|c|c|c|c|}
\hline \multirow{2}{*}{ RUN } & $\begin{array}{c}\text { CUTTING SPEED } \\
(\mathrm{m} / \mathrm{min})\end{array}$ & $\begin{array}{c}\text { FACTORS } \\
(\mathrm{mm} / \mathrm{rev})\end{array}$ & $\begin{array}{c}\text { DEPTH OF CUT } \\
(\mathrm{mm})\end{array}$ \\
\hline 1 & 50 & 0.9 & 0.1 \\
\hline 2 & 150 & 0.3 & 0.03 \\
\hline 3 & 100 & 0.6 & 0.3 \\
\hline 4 & 50 & 0.3 & 0.2 \\
\hline 5 & 100 & 0.6 & 0.2 \\
\hline 6 & 100 & 0.6 & 0.2 \\
\hline 7 & 100 & 1.1 & 0.2 \\
\hline 8 & 100 & 0.1 & 0.4 \\
\hline 9 & 100 & 0.6 & 0.2 \\
\hline 10 & 100 & 0.6 & 0.2 \\
\hline 11 & 100 & 0.6 & 0.1 \\
\hline 12 & 150 & 0.9 & 0.2 \\
\hline 13 & 100 & 0.6 & 0.2 \\
\hline 14 & 184 & 0.9 & 0.2 \\
\hline 15 & 16 & 0.6 & 0.1 \\
\hline 16 & 50 & 0.3 & 0.3 \\
\hline 17 & 150 & 0.9 & 0.3 \\
\hline 18 & 50 & 0.9 & 0.3 \\
\hline 19 & 150 & 0.3 & 0.2 \\
\hline 20 & 100 & 0.6 & \\
\hline
\end{tabular}

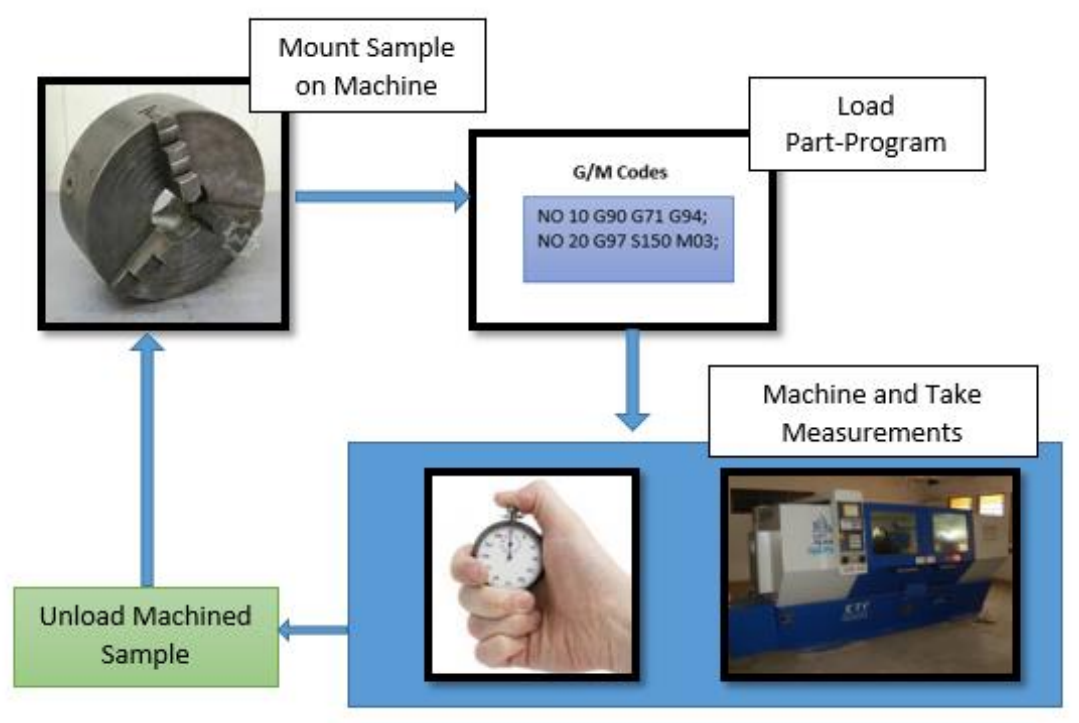

Figure 4: Cycle observed during machining of AISI 1090

\subsection{Experimental Procedure and Tests}

\subsubsection{Experimental Procedure}

The prepared steel samples were hardened by heating them in a furnace and quenched using brine, pure water and palm-oil. The hardened steel samples were thereafter mounted on a three-jaw-chuck lathe machine for the turning process (Figure 2). The machining cycle is as illustrated in the Figure 4. Twenty (20) machining runs were carried out altogether and were guided by the orthogonal array developed. Each run was repeated 3 times and the average data was reported. Each machining session was timed using a stopwatch and cutting time was fixed for 5 minutes. Surface roughness and material removal rate were measured and recorded using a profilometer and weighing balance, respectively. 


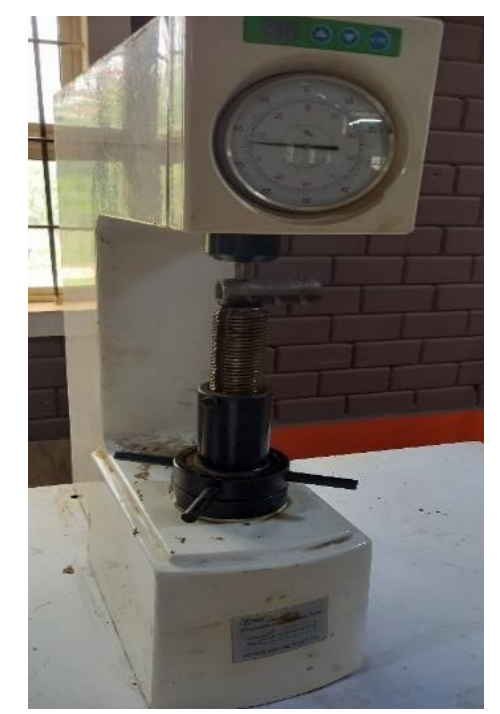

Figure 5: Sample on a Rockwell Hardness Tester

\subsubsection{Tests}

\section{a. Hardness Test}

The hardness value of the steel samples was determined using a Rockwell hardness testing machine resident in the Department of Civil Engineering Laboratory, Elizade University (Figure 5). The experiment was carried out at three intervals (before hardening, before machining and after machining) to allow for robust analysis. The sample surfaces were polished prior to test. The indenters were tungsten carbide hard metal balls with load 15 and 100 kgf, respectively. The procedure used by [8] was adopted for the hardness test.

\section{b. Surface Roughness Test}

The surface roughness values were measured using a profilometer. The surface of the specimen was cleaned before measurements were taken to reduce error. The surface measurement for each machining run was taken three times and the average value was reported to also reduce the incidence of error.

\section{c. Material Removal Rate Determination}

Material removal rate was calculated using Equation (1.0) [7]. The weight of the samples was measured before machining and after machining. The difference in weight was calculated and divided by machining time to determine the average material removal rate.

$$
M R R=\frac{w_{1}-w_{2}}{t}
$$

Where,

$$
\begin{aligned}
& \text { MRR = material removal rate } \\
& w_{2}=\text { final weight } \\
& w_{1}=\text { initial weight } \\
& t=\text { machining time }
\end{aligned}
$$

\section{RESULTS AND DISCUSSION}

\subsection{Hardness Test}

The hardness test result is as shown in Table 4. The hardness values for heat-treated samples were generally higher when compared with non-heat-treated samples. The highest hardness value of 250 HRB was recorded for steel bar sample quenched with pure water. This represents a sharp increase in hardness value when compared with same steel sample quenched in air (control) with a hardness value of $185 \mathrm{HRB}$.

Steel samples quenched with brine and palm-oil were found to have hardness values of $210 \mathrm{HRB}$ and $150 \mathrm{HRB}$, respectively. This results opines that pure water is a better quenchant for high carbon steels when hardness is required during heat treatment. This was in agreement with [8], [11] and [12] who all reported highest hardness when steel samples were quenched with water as compared with other quenchants. This result also agrees with [13] who reported water as a better quenching media when heat-treating carbon steels for an increase in hardness value. Palmoil had the lowest hardness value which is less ideal as a quenchant for HCS when hardness is an interest. 
Table 4: Hardness of the Quenched Samples

\begin{tabular}{|c|c|c|c|c|}
\hline Quenchant & Pure Water & Palm-Oil & Brine & Air \\
\hline Hardness Value (HRB) & 250 & 150 & 210 & 185 \\
\hline
\end{tabular}

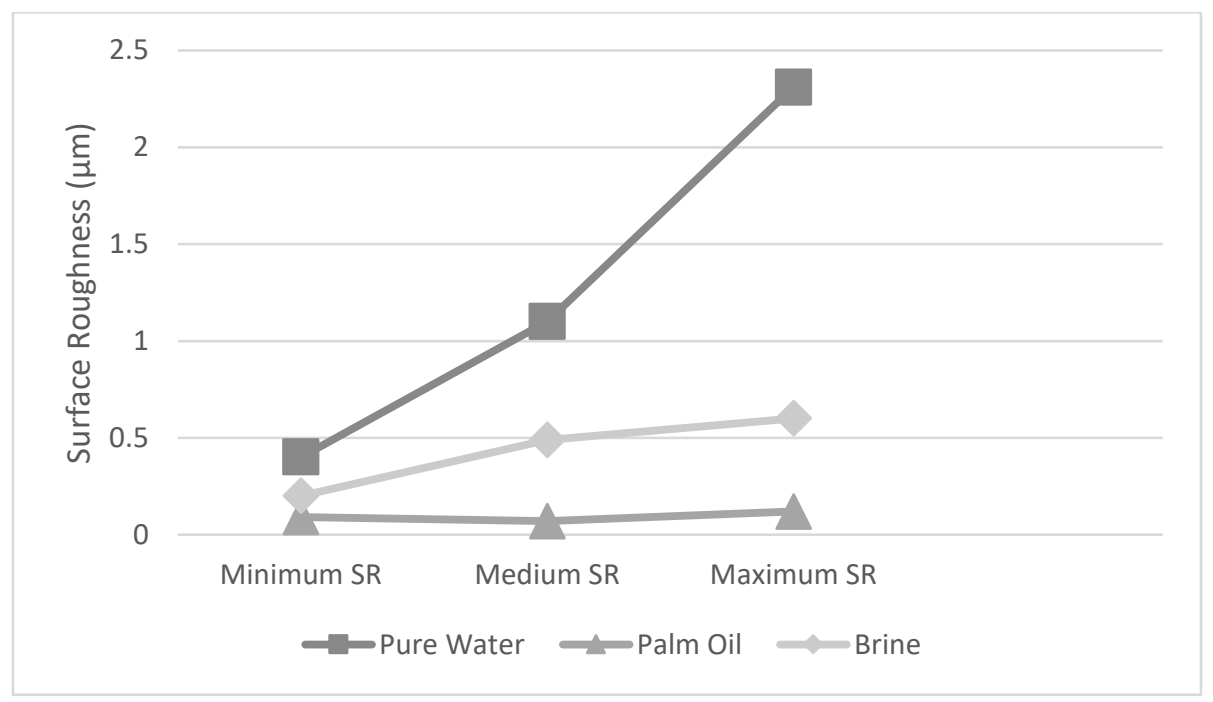

Figure 6: Surface Roughness for Various Quenching Media

\subsection{Surface Roughness Test}

The surface roughness result is presented in Figure 6. The highest surface roughness values were recorded for pure water which is understandable due to the higher hardness value results obtained from the hardness test, Post Machining minimum and maximum values of 0.401 .1 and $2.31 \mu \mathrm{m}$ were recorded for the steel sample quenched with pure water as compared with steel samples quenched with palm-oil and brine that recorded lower surfaces roughness values of $0.09,0.07 \& 0.12 \mu \mathrm{m}$ and $0.20,0.49 \& 0.60 \mu \mathrm{m}$ for minimum, medium and maximum values respectively.

From the analyses of the results, it was observed that there was no significant change in the surface roughness values for palm-oil quenched steel, though; a very sharp increase in surface roughness of pure water quenched steel was noticed. This increment is attributed to the increase in hardness of the quenched steel. This depict pure water as a poor quenching media when a better surface finish is desired. However, palm-oil was observed to perform better than brine and water with a moderate surface roughness value (min) of $0.09 \mu \mathrm{m}$ as against $0.2 \mu \mathrm{m}$ and $0.4 \mu \mathrm{m}$ for brine and pure water, respectively. This result therefore positioned palm oil as a better quenchant especially where reduced surface roughness is of a higher priority. The higher surface roughness values recorded for water can also be explained as resulting from the higher thermal conductivity of water $(0.669 \mathrm{w} / \mathrm{mK})$ as compared to palm oil $(0.167 \mathrm{w} / \mathrm{mK})$ and brine $(0.321 \mathrm{w} / \mathrm{mK})$ having lower heat conductivities. Hence, with higher thermal conductivity, water cooled the steel sample more rapidly resulting in a quick and vast formation of martensite which made the steel harder as compared to samples cooled by oil and brine with lower conductivities and slow cooling effect. This result agrees with [17] who reported that quenching heated steel with water resulted in increased hardness of the steel due to an increase in the martensite phase and [11] who reported palm-oil as a better quenching media when hardness value of carbon steels is to be reduced. This reduction in the ultimately results in a better surface finish as seen in Figure 4.

\subsection{Material Removal Rate Analysis}

The result of material removal rate (MRR) is presented in Figure 7. Generally, samples quenched in palm-oil was observed to return higher values of MRR with a maximum of $0.5124 \mathrm{~mm}^{3} / \mathrm{sec}$ as against samples quenched in brine and pure water having highest MRR values of $0.2514 \mathrm{~mm}^{3} / \mathrm{sec}$ and $0.1162 \mathrm{~mm}^{3} / \mathrm{sec}$, respectively. Results show that high values of MRR were recorded with high cutting speeds and feed rate. This result agrees with [2], [7] and [14] who all recorded increase in MRR with an increase in cutting speed and feed rate. Higher values of MRR observed during machining of steel samples quenched with palm-oil can be attributed to the lower strength possessed by this sample compared to other steel samples quenched with brine and pure water. Hence machinability of steel sample was improved by quenching in palm-oil. Interestingly, these highest MRR values for all the three quenching media was recorded at Run 14 which had highest values machining parameters (cutting speed $V=184 \mathrm{~m} / \mathrm{min}$, feed rate $f$ $=0.9 \mathrm{~mm} / \mathrm{rev}$ ). This further buttresses the point that higher values of cutting speed and feed rates results in higher 
values of material removal rates. An increase in MRR could subsequently reduce the energy consumed during machine as reported by [15].

An analysis of the effect of experimental factors on the surface roughness and material removal rate was carried out using signal to noise ratio. Smaller-is-better and Larger-is-better were chosen as design constraints for surface roughness and MRR respectively because a smaller surface roughness and larger MRR are indices for a better machining performance. Results (Figure 8 ) show that cutting speed and feed rate were the most significant factors influencing the material removal rate for all three steel samples quenched in various media. The effect of depth of cut was insignificant compared with other factors since it ranked lowest as seen in Table5.This result agrees with [16] who reported that cutting speed was the most influencing factor affecting surface roughness during machining.

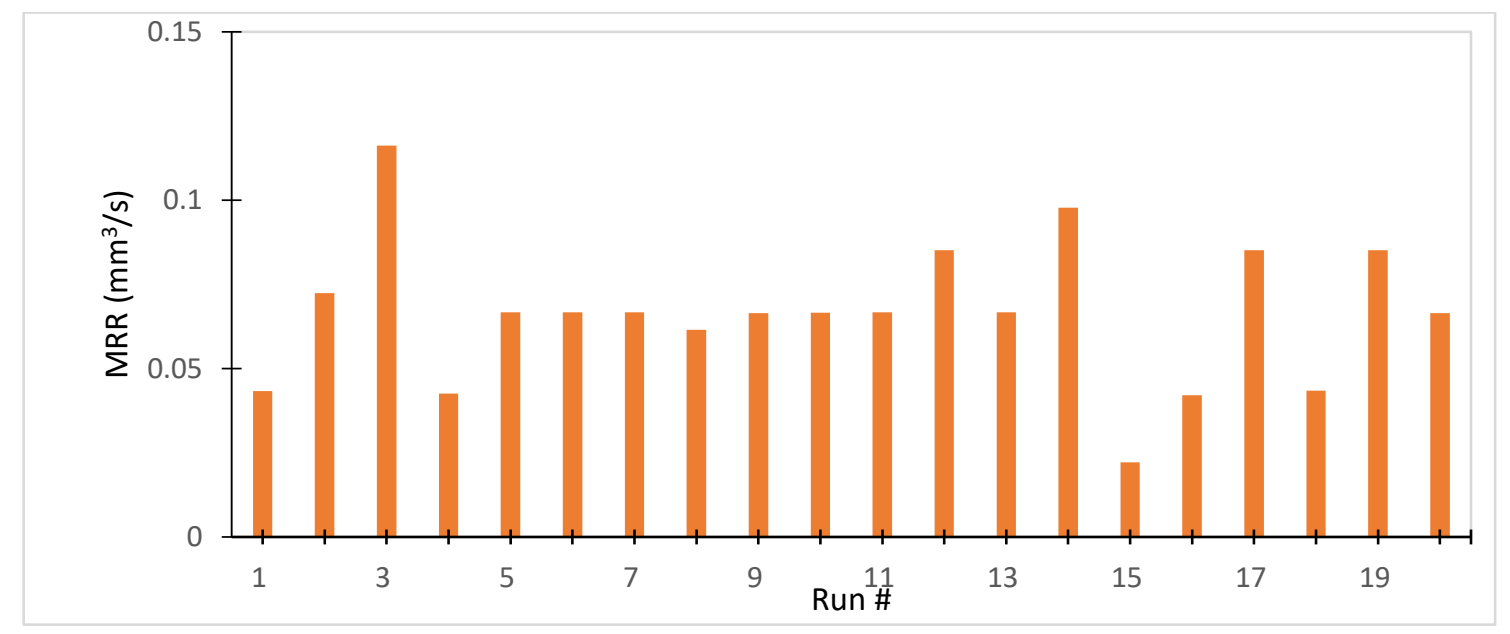

Figure 7: Material removal rate results for water quenching media

Table 5: Signal-to-Noise ratio response for Surface Roughness and MRR for Sample quenched with Brine

\begin{tabular}{|c|c|c|c|c|c|}
\hline \multirow{2}{*}{\begin{tabular}{|l|} 
Factors \\
Surface Roughness
\end{tabular}} & \multicolumn{3}{|c|}{ Levels } & \multirow[b]{2}{*}{ Delta } & \multirow[b]{2}{*}{ Rank } \\
\hline & 1 & 2 & 3 & & \\
\hline Cutting Speed & -25.32 & 25.46 & -23.52 & 1.94 & 2 \\
\hline Feed Rate & -26.07 & 23.52 & -23.48 & 2.59 & 1 \\
\hline Depth of Cut & -24.16 & -25.39 & -23.80 & 1.59 & 3 \\
\hline \multicolumn{6}{|c|}{ Material Removal Rate } \\
\hline Cutting Speed & 0.2829 & 0.2894 & 0.3550 & 0.0721 & 1 \\
\hline Feed Rate & 0.3529 & 0.3202 & 0.0528 & 0.0528 & 2 \\
\hline Depth of Cut & 0.3414 & 0.2887 & 0.3174 & 0.0527 & 3 \\
\hline
\end{tabular}




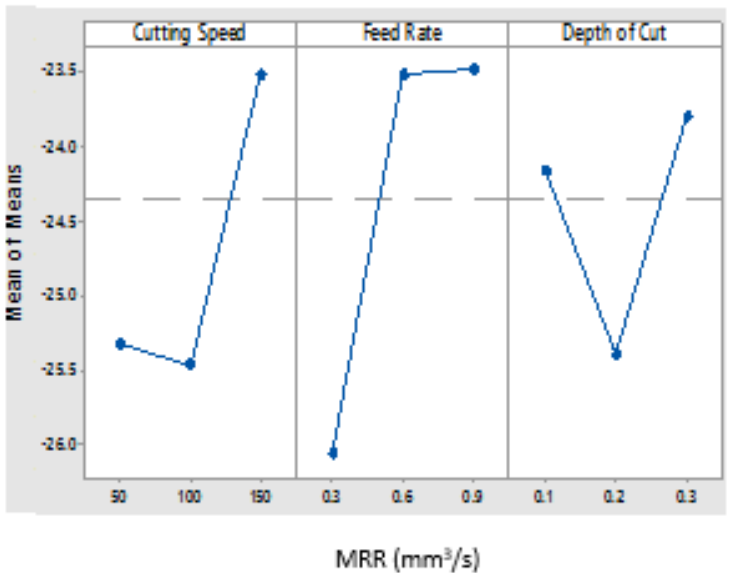

(a)

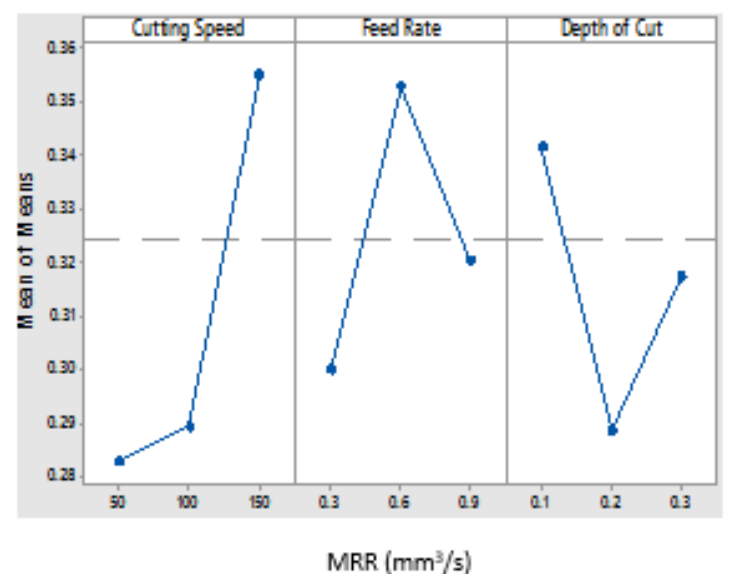

(b)

Figure 8: Main Effect of Factors on MRR for Various Quenching Media (a) Pure Water (b) Palm-oil

\section{CONCLUSIONS}

In summary, this work covered an experimental investigation on the effect of various using pure water, brine and palm-oil as quenchants during machining of heat treated high carbon steels. The effects on surface roughness, material removal rate and hardness values have been analysed. The experimental results obtained guided the following conclusions reached

(i) AISI 1090 quenched in pure water resulted in highest hardness value of $250 \mathrm{HRB}$, sample quenched in brine produced a moderate hardness value of 210 HRB. However, when quenched with palm-oil, Hardness value dropped to $150 \mathrm{HRB}$, slightly lower than the air cooled (control) sample of $185 \mathrm{HRB}$

(ii) AISI 1090 sample quenched with pure water had higher maximum surface roughness $(2.31 \mu \mathrm{m})$ than samples quenched with brine $(0.60 \mu \mathrm{m})$ and palm oil $(0.12 \mu \mathrm{m})$.

(iii) MRR was larger during machining of sample quenched with palm oil (MRR highest $\left.=0.5124 \mathrm{~mm}^{3} / \mathrm{sec}\right)$, moderate during machining sample quenched with brine (MRR highest $\left.=0.2514 \mathrm{~mm}^{3} / \mathrm{sec}\right)$ and lowest during machining sample quenched with pure water $\left(M_{R R}\right.$ highest $\left.=0.1162 \mathrm{~mm}^{3} / \mathrm{sec}\right)$.

\section{RECOMMENDATIONS}

Based on the conclusions reached from the study, the following recommendations are hereby made:

(i) Pure water is preferred as quenchant only when there is a need to increase hardness value of AISI 1090;

(ii) Palm-oil is the preferred quenchant during heat treatment of AISI 1090 to obtain the best surface finish during machining; and

(iii) Palm-oil is a preferred quenchant during heat treatment of AISI 1090 if the aim is to improve machinability via an increase in MRR.

\section{ACKNOWLEDGEMENT}

Authors will like to appreciate the technologists in central workshops of Elizade University and University of Ilorin for their support all through this study.

\section{REFERENCES}

1. Abdulkareem, S., Busari, R. A., Fashola, L. A and Madu, I. A. (2020). Characteristics of Notched High Strength Materials under Tension, Torsion and Impact Loading. International Journal of Engineering Materials and Manufacture, 5(3), 68-75.

2. Zheng, H.Y. and Liu, K. (2013), Machinability of Engineering Materials, Handbook of Manufacturing Engineering and Technology DOI 10.1007/978-1-4471-4976-7_2-1

3. Abdulkareem, S., Babatunde, M. A., Ogedengbe, T.S. and Adegun, I.K. (2020), Effect of Some Thermodynamic Properties of Cutting Fluids on Machinability of Carbon Steel, FUOYE Journal of Engineering and Technology, 5(2), 2579-0617

4. Abdulkareem, S., Ogedengbe, T. S., Aweda, J.O., Ajiboye, T. K., Khan, A. A., Babatunde, M. A. (2019), Investigation on Effect of Material Compositions on Machinability of Carbon Steels, Journal of Physics: Conference Series, 1378, 022046 IOP Publishingdoi:10.1088/1742-6596/1378/2/022046

5. Ogedengbe, T.S., Yezeed, O. A., Yussouff, A.A. (2019), Effect of Annealing On Machinability of Grey Cast Iron, Journal of Engineering and Technology, 10(1) 
6. Isamotu, O.F., Jacob, V.O., Oriaifo, M.A., Raji, K.M., Egu, I.A., Aluko, J.B. (2020), Comparative Analysis of Red Oil and Palm Kernel Oil Quenching Media for Low Carbon Steel, International Journal of Engineering Applied Sciences and Technology, 4(12), 67-76

7. Verdeja, L.F., Verdeja, J.I., \& González, R. (2009), Machinability Improvement through Heat Treatment in 8620 Low-Carbon Alloyed Steel, Machining Science and Technology, doi: 10.1080/10910340903451480.

8. Lu, Y., Sisson, R.D., Rong, Y.K. (2015), Critical Heat Transfer Coefficient Test for Gas Quench Steel Hardenability, Proceedings of the 28th ASM Heat Treating Society Conference October 20-22, Detroit, Michigan, USA, 490494.

9. Ogedengbe, T.S., Abdulkareem, S., Aweda, J.O. (2018), Effect of Coolant Temperature on Machining Characteristics of High Carbon Steel, Covenant Journal of Engineering Technology 1(1), 73-86.

10. Hande, G., Ertan, R., Özcan, R. (2012), Influence of Heat Treatment Parameters on the Microstructure and Mechanical Properties of Boron-Alloyed Steels, Materials Testing, 54(9), 1-9.

11. Onyenanu, I.U., Ignatius, Ekengwu, I.E., Mobic, I.M. (2015), Investigation of the Microstructure and Mechanical Properties of Quenched - Heat affected Zones of Mild Steel Weldments, 7(5), 143-151.

12. Ndaliman M.B. (2006), An Assessment of Mechanical Properties of Medium Carbon Steel under Different Quenching Media, Assumption University Journals. 10(2), 100-104.

13. Grinshin, S.A, and Churyukin, Y.N. (2016) Evaluation of the Cooling Capacity of Quenching Media Based on Water. Metal Sci. Heat Treat. 28(10), 744-745.

14. Shah, A.H.A., Azmi, A.I., Khalil, A.N.M. (2016). Grey relational analyses for multi-objective optimization of turning S45C carbon steel, IOP Conf. Series: Materials Science and Engineering 114012023 doi:10.10088/1757899X/114/1/012023.

15. Ogedengbe T.S. (2019), Sustainable Machining Processes Through Optimization of Process Parameters, International Journal of Engineering Materials and Manufacturing, 4(1), 22-26, doi: 10.26776/ijemm.04.01.2019.03

16. Giovanna R., Sergio R. \&Luigino F. (2019), Roller burnishing of Ti6Al4V under different cooling/lubrication conditions and tool design: effects on surface integrity, The International Journal of Advanced Manufacturing Technology, 106(2), 431-440, https://doi.org/10.1007/s00170-019-04631-z.

17. Khansaa D.S. and Basaam A.A. (2018), Effect of Quenching Media on Mechanical Properties of Medium Carbon Steel 1030, Journal of University of Babylon, Engineering Sciences, 26(2), 214-222. 